\title{
International Space Station (ISS) Internal Active Thermal Control System (IATCS) New Biocide Selection, Qualification and Implementation
}

\author{
Mark E. Wilson and Harold Cole \\ The Boeing Company
}

Tony Rector, John Steele, and Jerry Varsik

Hamilton Sundstrand Space Systems International, Inc.

The Internal Active Thermal Control System (IATCS) aboard the International Space Station (ISS) is primarily responsible for the removal of heat loads from payload and system racks. The IATCS is a water based system which works in conjunction with the EATCS (External ATCS), an ammonia based system, which are interfaced through a heat exchanger to facilitate heat transfer. On-orbit issues associated with the aqueous coolant chemistry began to occur with unexpected increases in $\mathrm{CO}_{2}$ levels in the cabin. This caused an increase in total inorganic carbon (TIC), a reduction in coolant $\mathrm{pH}$, increased corrosion, and precipitation of nickel phosphate. These chemical changes were also accompanied by the growth of heterotrophic bacteria that increased risk to the system and could potentially impact crew health and safety. Studies were conducted to select a biocide to control microbial growth in the system based on requirements for disinfection at low chemical concentration (effectiveness), solubility and stability, material compatibility, low toxicity to humans, compatibility with vehicle environmental control and life support systems (ECLSS), ease of application, rapid on-orbit measurement, and removal capability. Based on these requirements, ortho-phthalaldehyde (OPA), an aromatic dialdehyde compound, was selected for qualification testing. This paper presents the OPA qualification test results, development of hardware and methodology to safely apply OPA to the system, development of a means to remove OPA, development of a rapid colorimetric test for measurement of OPA, and the OPA on-orbit performance for controlling the growth of microorganisms in the ISS IATCS since November 3, 2007. 